\title{
THE ROLE OF MAGNETIC RESONANCE IMAGING FOR ACUTE ISCHEMIC STROKE
}

\author{
Daniel Sanak ${ }^{\mathrm{a}}$, David Horak ${ }^{\mathrm{b}}$, Roman Herziga ${ }^{\mathrm{a}}$, Petr Hlustik ${ }^{\mathrm{a}}$, Petr Kanovsky ${ }^{\mathrm{a}}$
}

\author{
Stroke Centre, \\ a Department of Neurology and \\ ${ }^{b}$ Radiology, Faculty of Medicine and Dentistry Palacky University Olomouc and University Hospital, Olomouc, Czech \\ Republic \\ e-mail:daniel.sanak@fnol.cz
}

Received: March 3, 2009; Accepted: July 14, 2009

Key words: Ischemic stroke/Thrombolysis/Magnetic resonance imaging/Mismatch

Background: Although computed tomography (CT) is still considered to be the gold standard of brain imaging before thrombolysis, new reperfusion strategies in acute ischemic stroke lead to more extensive use of magnetic resonance imaging (MRI).

Methods and results: Diffusion- (DWI) and perfusion-weighted (PWI) MRI with MRI angiography are considered the most important examinations in diagnosis of acute ischemic stroke before reperfusion therapy. The effort to extend strict therapeutic time window resulted in the PWI/DWI mismatch concept, established to identify the presence of ischemic penumbra. Nevertheless, a lack of standards for methodology and analysis and existence of different alternative interpretations of such mismatch still present significant limitations of its use in routine clinical practice.

Conclusion: MRI allows accurate diagnosis of the infarct lesion, detection of cerebral arterial occlusion or significant stenosis with evaluation of actual collateral flow and may also display certain reversible ischemic changes. However, the main objective for MRI still remains: improvement of non-invasive rapid and accurate identification of brain tissue at risk for infarction, which may be salvaged by safe and effective reperfusion therapy.

Thrombolysis is presently the only standardized causal therapy for acute ischemic stroke and is considered a safe and effective treatment method ${ }^{1}$. Urgent brain imaging is required to exclude other causes of neurological symptoms before thrombolysis. Computed tomography (CT) of the brain, which was used in most previous clinical trials is largely performed in routine clinical practice and is still recommended as a gold imaging standard before reperfusion therapy ${ }^{1}$. Reliable exclusion of intracerebral (ICH) or subarachnoidal hemorrhage (SAH) as the cause of acute neurological symptoms before rt-PA treatment is the main benefit of CT. On other hand, the role of CT in detection of acute ischemic changes may be at least problematic. At the beginning of the "CT era" in the 1980s, CT findings were considered negative within the first 12 hours from stroke onset regarding presence of early ischemic changes ${ }^{2,3}$. Thanks to the availability of new CT machines with high spatial resolution in the last decades, a widely respected consensus concerning ability of CT to detect certain (ischemic) changes on brain scans within first 6 hours from stroke onset was created by the neuroradiological community. Nevertheless, the sensitivity of detection of these "early changes" highly varies (between 53 to $92 \%$ ) and CT is not able to differentiate the age of these changes ${ }^{4-6}$.

Therapeutic strategies for acute ischemic stroke changed dramatically during the last few years and adequate brain imaging has become crucial for optimal patient selection for specific reperfusion treatment. The fact that up to $20 \%$ of diagnoses of ischemic stroke at patient admission are incorrect and that even some of these patients with symptoms mimicking stroke are treated with rt-PA documents very clearly the importance and necessity of accurate stroke diagnosis ${ }^{7,8}$. This is where magnetic resonance imaging (MRI) became useful. Until the beginning of 1990s, MRI was reserved mainly for the subacute phase of ischemic stroke, because the most widely available conventional sequence - T2-weighted imaging - shows infarct lesions only after 6-8 hours as a hyperintense zone $\mathrm{e}^{9,10}$ and a T1-weighted sequence even later and as a hypointense lesion ${ }^{11}$. Conventional MRI offered mainly higher resolution capability for detection of relatively smaller infarcts, especially in the brain stem and cerebellum compared to $\mathrm{CT}^{12,13}$. The use of urgent MRI in acute stroke was also limited for generally prevailing pessimism for low sensitivity in the detection of acute ICH or SAH compared to CT. Fortunately, this pessimism disappeared completely when more accurate MRI machines and new echoplanar sequences $(\mathrm{T} 2 *)$ capable of safely detecting brain hemorrhage became established in clinical practice ${ }^{14-17}$.

Development of MRI echoplanar techniques facilitated the creation of multiparametric MRI protocols containing several different sequences able to detect accurately not only the infarct lesion, but also significant arterial occlusion or stenosis in the circle of Willis, and permitted evaluation of the actual collateral flow and reversible ischemic changes. These multiparametric protocols were 
used in several clinical trials to assess their efficacy and benefits for indication of reperfusion therapy ${ }^{18-22}$.

Several MRI sequences, their imaging and technical specifications and mainly their clinical benefit for acute stroke diagnosis will be discussed next.

\section{Diffusion-weighted imaging (DWI)}

DWI is crucial for the detection of acute ischemic changes. During ischemic neuronal damage, prompt failure of high-energetic cellular membrane metabolism occurs with membrane pump destruction. This leads to decreased diffusion of $\mathrm{H}_{2} \mathrm{O}$ molecules in the context of membrane permeability decrease or to $\mathrm{H}_{2} \mathrm{O}$ molecules locked in the cells in the course of developing cytotoxic edema. The decrease of diffusion of $\mathrm{H}_{2} \mathrm{O}$ molecules is quantified using apparent diffusion coefficient (ADC) and leads in this case to its decrease represented as a hypointense zone on an ADC map and a hyperintense lesion on DWI scans (Fig. 1). These hyperintense changes represent, according to majority oponion, immediate irreversible ischemic neuronal damage ${ }^{23-27}$, namely within several minutes after arterial occlusion ${ }^{28,29}$. In some cases, if the cerebral blood perfusion is very rapidly restored, these changes could be potentially reversible; e.g., in patients treated with thrombolysis ${ }^{30-34}$ or in the case of transient ischemic attack (TIA) ${ }^{35}$. DWI is much more sensitive and accurate in detection of acute ischemic changes compared to conventional $\mathrm{CT}^{36,37}$. Parameter $b$-value determines the sensitivity in measurement of diffusion weighting. B-value is calculated from the power and the duration of diffusion gradients and from the time interval between gradient pulses. Higher $b$-value means higher sensitivity for detection of diffusion changes. In addition to diffusion measurement, quantification of ADC and creation of an ADC

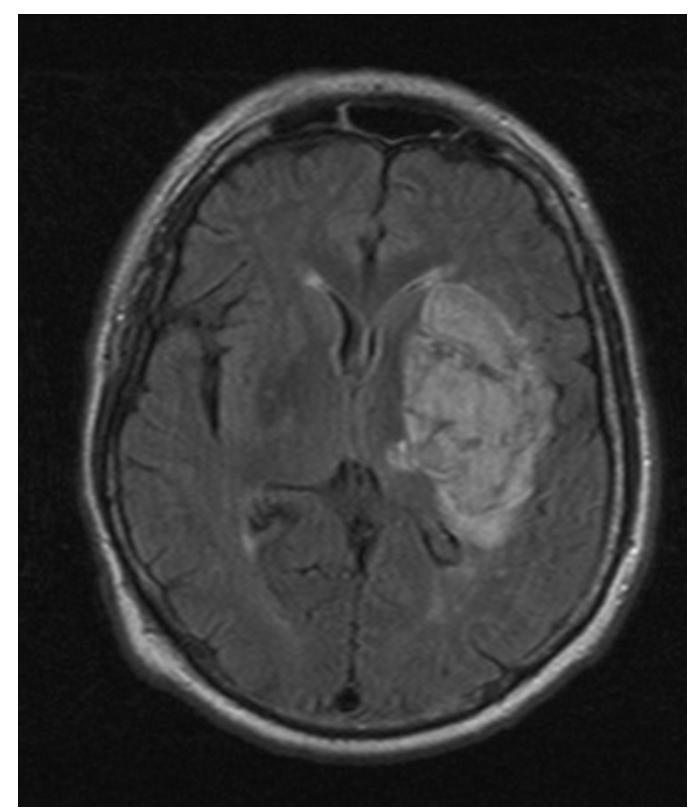

Fig. 2A. FLAIR sequence, acute large hypertonic intracerebral hemorrhage in left basal ganglia and capsula interna; 100 minutes from symptoms onset.

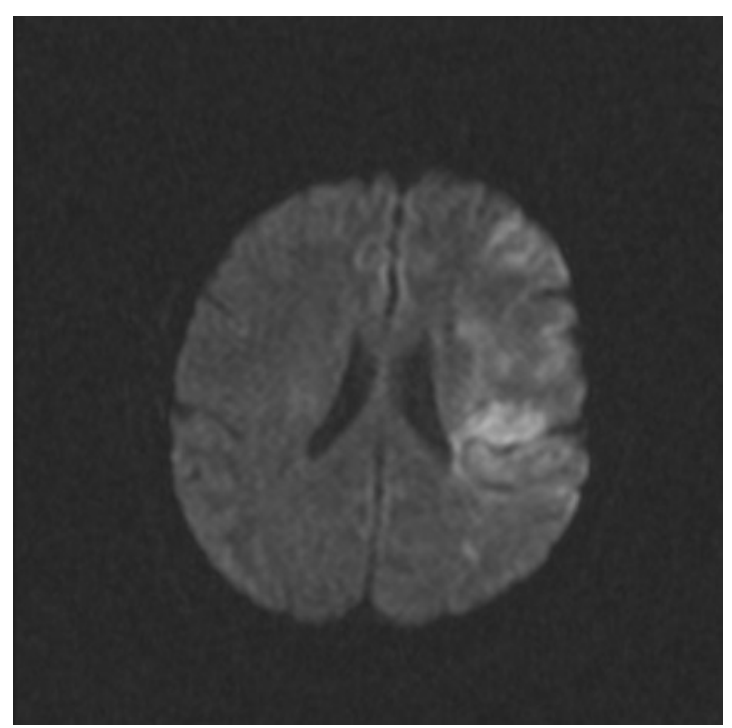

Fig. 1. DWI sequence (b-1000), acute ischemic stroke in territory of left middle cerebral artery; 85 minutes from stroke onset.

map are also possible. In the ADC map, single voxels represent quantitative diffusion measurement. The zone of low diffusion appears hypointense and, by contrast, areas of high $\mathrm{H}_{2} \mathrm{O}$ molecule diffusion are hyperintense (cerebrospinal fluid) on this map. Significant ADC reduction (about 40-50\%) representing infarct changes correlates very well with histopathological findings ${ }^{38,39}$. DWI is also useful in patients with acute neurological symptoms and multiinfarct brain lesions of different age; it can identify the acute lesion which corresponds to the present clinical symptoms ${ }^{40,41}$.

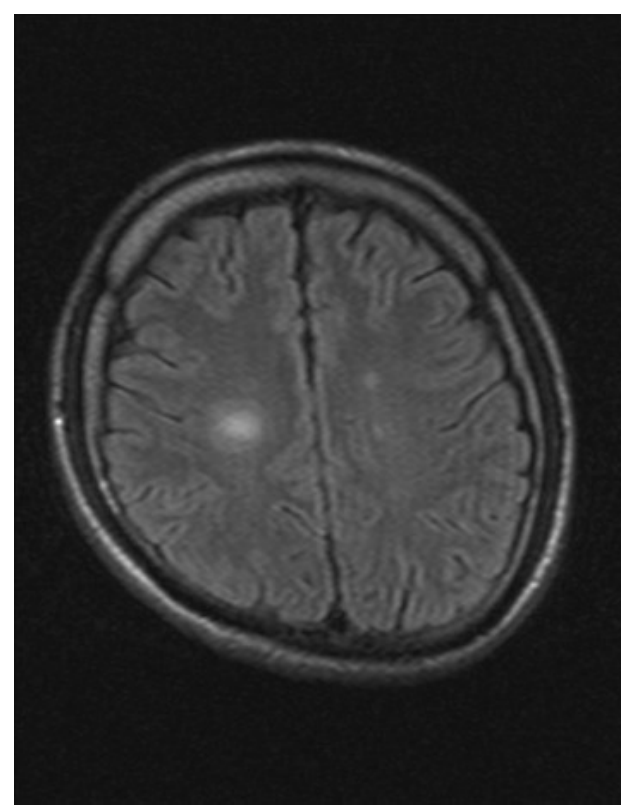

Fig. 2B. FLAIR sequence, small demyelinization lesion in right parietal cortex, clinical symptoms: leftsided moderate central hemiparesis persists 125 minutes. 
Quantification of initial infarct volume on DWI may be used for prediction of clinical outcome in patients with stem occlusion of middle cerebral artery (MCA) treated with intravenous/intra-arterial thrombolysis. The results of our retrospective analysis showed that patients with initial infarct volume over $70 \mathrm{ml}$ had significantly higher probability of poor clinical outcome after thrombolysis ${ }^{42}$.

\section{Fluid Attenuated Inversion Recovery (FLAIR)}

This sequence uses so-called preparation inverse $180^{\circ}$ radiofrequency pulse and a long-term inverse time for reduction of cerebrospinal fluid signal. The resulting T2weighted images with hypointense cerebrospinal fluid allow better detection of hyperintense pathological lesions localized closely to external fluid cisterns or ventricles.

Infarct lesion is visible on FLAIR as a hyperintense zone not earlier than 5 to 6 hours from stroke onset, when vasogenic edema develops and water content increases significantly in the damaged tissue. FLAIR may differentiate subacute and chronic ischemic changes and other types of non-ischemic etiology of neurological symptoms (e.g. tumor, multiple sclerosis etc. $)^{43-46}$ (Fig. 2).

\section{$\mathrm{T} 2$ *}

$\mathrm{T} 2 *$ (star) is a very important sequence for detection of hemorrhage. Degradation products of hemoglobin (deoxyhemoglobin and hemosiderin) have paramagnetic properties and cause local inhomogeneity of the magnetic field, which results in signal loss on T2* scans (dark lesion $)^{47}$. T2* may also detects microbleeds and early hemorrhagic transformation of brain infarct ${ }^{48,49}$. These findings exclude the patients from eventual thrombolytic therapy. Sometimes, for practical reasons of shortening the examination time by about 3 to 4 minutes the "classic" T2* may be replaced by a set of gradient echo EPI

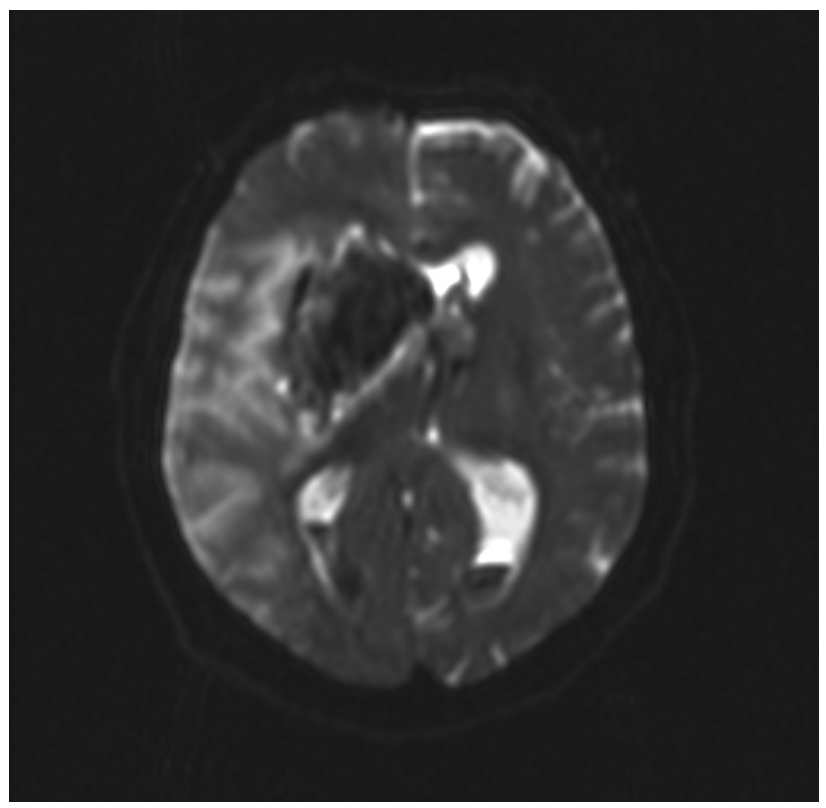

Fig. 3. EPI-DWI sequence (b-0), intracerebral hemorrhage (hypointense) in infarct lesion (hyperintense) in right cortex.

images with $b=0$, which is part of some EPI-DWI trace sequence protocols ${ }^{42}$. These sequences have lower spatial resolution, but they are highly sensitive for detection of acute hemorrhage (Fig. 3).

\section{Magnetic Resonance Angiography (MRA)}

MRA is used to display the arteries of the circle of Willis using "time of flight" (TOF) technique ${ }^{50}$. The TOF technique detects "new flowing" non-saturated spins in a predefined excited stationary layer during the blood flow. These protons are displayed as a hyperintense zone

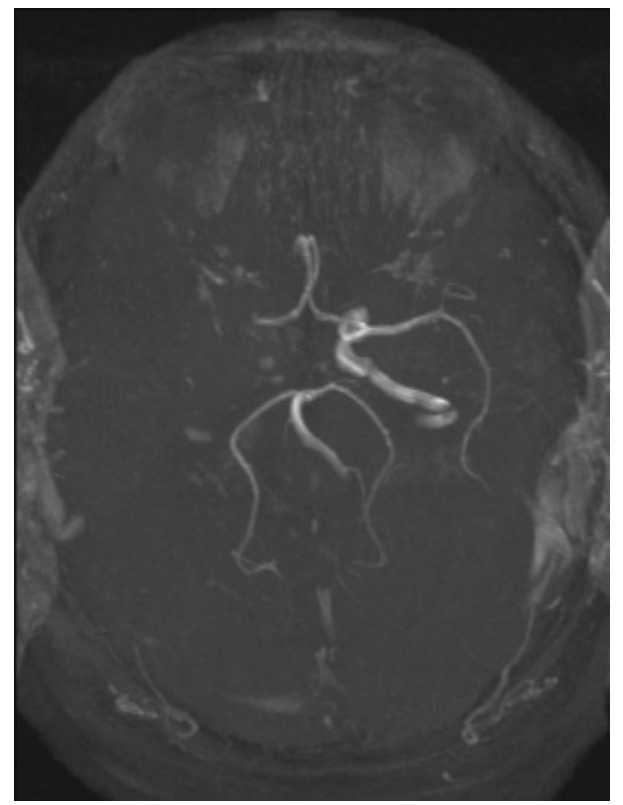

Fig. 4A. 3D TOF MRA sequence, occlusion of intracranial portion of right internal carotid artery.

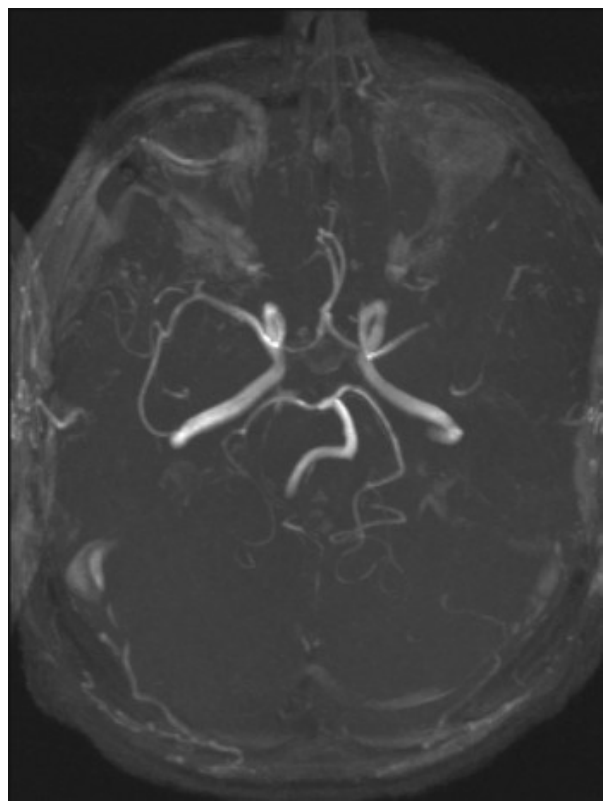

Fig. 4B. 3D TOF MRA sequence, occlusion of left middle cerebral artery (M1). 
on a hypointense background. Maximum intensity projection (MIP) results in an angiogram ${ }^{51}$. Obtained basic sublayers may be visualized directly into 2D scans or they may be processed in three-dimensions into high-quality 3D image of the Willis circle, which shows arterial occlusion or significant stenosis ${ }^{52-55}$ (Fig. 4).

The reliability of 3D TOF MRA was repeatedly confirmed by comparison with digital subtraction angiography (DSA), CT angiography (CTA) and duplex sonography in past ${ }^{56-57}$.

3D TOF MRA may also display the collateral flow in occlusion of MCA stem or internal carotid artery $(\text { ICA })^{58,59}$. A possible limitation is the less accurate imaging of smaller and more peripheral branches of cerebral arteries compared to DSA and $\mathrm{CTA}^{55}$, although MRA provides enough information about cerebral arteries for accurate diagnosis of ischemic stroke ${ }^{60,61}$.

Ischemic stroke may also be caused by pathology in the extra-cranial portion of carotid and vertebral arteries, most commonly by occlusion or significant stenosis of the internal carotid artery (ICA). For this reason, MRA of extra-cranial portion of cerebral arteries is added to the examination protocol in some stroke units. 3D TOF MRA is used on a standard basis and its accuracy was also evaluated using of comparison DSA and CTA ${ }^{62}$. A disadvantage of non-contrast MRA is the long duration of the examination, which is typically about 10 minutes. Therefore a different MRA technique using intravenous administration of contrast paramagnetic agent (contrastenhanced magnetic resonance angiography, CE-MRA) began to be used in the last decade. CE-MRA significantly reduces the examination time and moreover, is capable of very accurate quantification of the degree of stenosis, which is comparable to invasive DSA thanks to using special techniques with high spatial resolution and special post-processing software ${ }^{63-67}$.

\section{Perfusion-weighted imaging (PWI)}

PWI represents a set of techniques, which can detect hemodynamic changes in brain tissue on a microvascular level. A paramagnetic contrast agent (gadolinium) is applied as an intravenously administrated bolus. Subsequent signal changes, which are caused by contrast agent passage through brain tissue, are detected by ultra-fast MR sequences ${ }^{68}$. The most visible signal changes are caused by difference of contrast agent concentration in extra/ intravascular space. Gradient echo-planar imaging (EPI) is mostly used in PWI.

The passage of contrast agent through brain causes signal decrease. In ischemic tissue perfusion is decreasing and therefore the contrast agent has minimal or no concentration in this ischemic zone and signal is relatively increased $^{69}$. Although the dynamics of signal changes provide some information about cerebral microcirculation, the relative signal loss does not correlate directly with any physiological parameter. The derivation of a "signal - time" curve and "concentration of contrast agent - time" curve acquired during first passage of contrast agent are needed to calculate (semi-) quantitative parameters of cerebrovascular hemodynamics ${ }^{69}$. The results of these complicated derivations are several hemodynamic parameters: cerebral blood flow $(\mathrm{CBF})$, cerebral blood volume (CBV). Two other parameters are derived from the "concentration of contrast agent - time" curve. First is the "mean transit time" (MTT); time interval when signal returns to baseline after passage of the contrast agent. Second is the "time to peak" (TTP); time when the concentration of gadolinium becomes maximal in the region of interest ${ }^{70}$. These parameters are mostly used in clinical practice only as qualitative indices of cerebral perfusion in the form of color maps because of highly time-consuming post-processing calculations of parameter values ${ }^{71}$.

\section{Ischemic penumbra and the mismatch concept}

Time is one of the most important limitations for more extensive use of intravenous thrombolysis in acute stroke patients. Recently updated guidelines published on the internet $^{72}$ allow the administration of IVT within first 4.5 hours from stroke onset based on results from ECASS III trial ${ }^{73}$, however such rt-PA administration is off the current European labeling. Nevertheless, imaging technologies provide information about the presence of the potentially salvageable ischemic brain tissue until several hours from stroke onset ${ }^{74-76}$. This zone is called ischemic penumbra and represents brain tissue, which is at risk for infarct growth and which is potentially salvageable by early recanalization therapy ${ }^{77}$. Biochemically, penumbra is defined as a zone of suppressed protein synthesis caused by blood hypoperfusion, but without irreversible energetic damage with ATP depletion. Tissue which is only hypoperfused without suppression of protein synthesis is not at risk for infarct growth. Logically, brain tissue should be salvaged before the onset of decrease in protein synthesis and of ATP depletion. However, there is no routinely available technology, which is capable to display these biochemical changes. Presently, only positron emission tomography (PET) can detect accurately the real ischemic penumbra using radioactive oxygen $\left({ }^{15} \mathrm{O}\right)$ with short halftime ${ }^{78-80}$. PET penumbra is defined as zone of critical decrease of blood flow, but with preserved $\mathrm{O}_{2}$ consumption with evidence of high value of $\mathrm{O}_{2}$ tissue extraction ${ }^{81}$.

The development of new MRI techniques encouraged also the identification of ischemic penumbra using MRI. The concept of PWI/DWI mismatch appeared as a result of MRI technical improvement. Mismatch was defined as a difference between PWI lesion surface area and hyperintense DWI zone surface area on respective MRI scans and this surface area difference should represent tissue at risk for infarct growth ${ }^{82-85}$. Patients with ischemic penumbra presented on MRI may have higher profit from thrombolytic therapy several hours after stroke onset compared to patients without detected penumbra ${ }^{86-88}$.

The frequent use of this mismatch concept may indicate its great reliability and accuracy for decision to perform thrombolysis beyond standard 3-hour therapeutic window. However, several facts should be discussed because they may challenge this concept.

Although hyperintense changes displayed on DWI are still considered to be a marker of irreversible damage of brain tissue $e^{23-27}$ present immediately after arterial 
occlusion $^{28,29}$, cases of significant DWI lesion regression are repeatedly reported in patients with rapidly restored cerebral perfusion after thrombolysis ${ }^{30-34}$ or in the case of TIA ${ }^{35}$.

Furthermore, several aspects of PWI are still being discussed: choice of the most accurate and optimal (,costeffective“) MRI technique for PWI, assessing a reliable post-processing method for quantification of hemodynamic parameters, which better characterize tissue at risk of infarction - penumbra ${ }^{89-91}$; PWI cannot differentiate benign oligemia and real penumbra reliably ${ }^{92}$. Nonstandardized design of the corresponding MRI sequences still limits objective interpretation of the achieved results. Not only several doses of contrast agent, but also different sequence techniques and different methods of parameter measurements are used during PWI examination and it is still not clear which of them should be used in routine clinical practice ${ }^{93}$. Analogously, the concept of PWI/DWI mismatch is still largely being discussed. Some authors consider it as an approximation of the real penumbra ${ }^{77}$, different definitions and methods of mismatch quantification are problematic for other authors ${ }^{93}$. At present, several definitions are established; some authors defined mismatch as the absolute difference between PWI and DWI lesion ${ }^{82,83,94}$, others as the difference between $50 \%$ of PWI lesion and DWI lesion ${ }^{95}$. The mismatch volume was measured in most trials directly on MRI scanner monitor and some evaluated the volume only visually ${ }^{84,85}$. These facts which limit routine use of mismatch lead to creation of other new concepts. One of them is the mismatch between the degree of neurological deficit in NIHSS and the initial infarct volume on DWI - clinical-diffusion mismatch (CDM). CDM was defined as presence of NIHSS $\geq 8$ and infarct volume on DWI $\leq 25 \mathrm{ml}^{95}$. CDM was compared to PWI/DWI mismatch and a significant agreement with high specificity and predictive value was found ${ }^{96}$. Contrariwise, Lansberg et al. reported that clinical improvement after IVT performed in patients between 3 and 6 hours from stroke was significantly correlated to the presence of PWI/DWI mismatch, but not to presence of $\mathrm{CDM}^{97}$. Our retrospective analysis of 79 patients treated with IVT within 3 hours showed better clinical results in patients with present CDM before thrombolysis ${ }^{98}$.

\section{CONCLUSION}

At present, MRI allows accurate diagnostics of acute brain infarct lesion (actual size, localization), detection of occlusion or significant arterial stenosis and evaluation of actual collateral flow. MRI can also detect some reversible ischemic changes. This information may help better identify the patients with probably higher benefit from thrombolysis, especially beyond the standard therapeutic time window ${ }^{74-77,86-88,98}$.

However, the main objective for MRI still remains: the improvement of non-invasive rapid and accurate identification of brain tissue at risk for infarction, which may be salvaged by safe and effective reperfusion therapy.

\section{REFERENCES}

1. The European Stroke Organization (ESO) Executive Committee and the ESO Writing Committee. Guidelines for management of ischemic stroke and transient ischemic attack 2008. Cerebrovasc Dis 2008; 25: 457-507.

2. Gilman S. Imaging the brain. First of two parts. N Eng J Med 1998; 338: $812-820$.

3. Gilman S. Imaging the brain. Second of two parts. N Eng J Med 1998; 338: 889-896.

4. Horowitz SH, Zito JL, Donnarumma R, Patel M, Alvir J. Computed tomografic -angiographic findings within the first five hours of cerebral infarction. Stroke 1991; 22: 1245-1253.

5. Tomura N, Lemura K, Knutami A, Fujita H, Gitano S, Shishido F. Early CT findings in cerebral infarction: obscuration of the lentiform nucleus. Radiology 1988; 168: 463-467.

6. von Kummer R, Meyding-Lamade U, Forsting M, Rosin L, Reke K. Hacke W, et al. Sensitivity and prognostic value of early CT in occlusion of the middle cerebral artery trunk. Am J Neuroradiol 1994; 15: 9-15.

7. Liman RB, Wirkowaki E, Alvir J, Rao TH. Conditions that mimic stroke in the emergency department: implications for acute stroke treatment trials. Arch Neurol 1995; 52: 1119-1122.

8. Katzan IL, Furlan AJ, Lloyd LE, Frank JI, Harper DL, Hinchey JA, et al. Use of tissue-type plasminogen activator for acute ischemic stroke: the Cleveland area experience. JAMA 2000; 283: 1151-1158.

9. Crain MR, Yuh WTC, Greene GM, Loes DJ, Ryals TJ, Sato Y, et al. Cerebral ischemia: evaluation with contrast-enhanced MR imaging. AJNR Am J Neuroradiol 1991; 12: 631-639.

10. Mohr JP, Biller J, Hilal SK, Yuh WT, Tatemichi TK, Hedges S, et al. Magnetic resonance versus computed tomographic imaging in acute stroke. Stroke 1995; 26: 807-812.

11. Unger EC, Gado MH, Fulling KF, Littlefield JL. Acute cerebral infarction in monkeys: AN experimental study using MR imaging. Radiology 1987; 162: 789-795.

12. Brant-Zawadzki M, Solomon M, Newton TH, Weinstein P, Schmidley J, Norma D: Basic principles of magnetic resonance imaging in cerebral ischemia and initial clinical experience. Neuroradiology 1985; 27: 517-520.

13. Dewitt LD: Clinical use of nuclear magnetic resonance imaging in stroke. Curr Cone Cerebrovas Dis/Stroke 1985; 20: 25-29.

14. Patel R, Edelman R, Warach S. Detection of hyperacute primary intraparenchymal hemorrhagie by magnetic resonance imaging. Stroke 1996; 27: 2321-2324.

15. Atlas SW, Thulborn KR. MR detection of hyperacute parenchymal hemorrhage of the brain. AJNR Am J Neuroradiol 1998; 19: 14711507.

16. Schellinger PD, Jansen O, Fiebach JB, Hacke W, Sartor K. A standardized MRI stroke protocol: comparison with CT in hyperacute intracerebral hemorrhage. Stroke 1999; 30: 765-768.

17. Singer MB, Atlas SW, Drayer BP. Subarachnoid space disease: a diagnosis with fluid-attenuated inversion recovery MR imaging and comparison with gadolinium-enhaced spin-echo MR imaging - blinded leader study. Radiology 1998; 208: 417-422.

18. Schellinger PD, Jansen O, Fiebach JB, Pohlers O, Ryssel H, Heiland S, et al. Feasibility and practicality of MR imaging of stroke in the management of hyperacute cerebral ischemia. AJNR Am J Neuroradiol 2000; 21: 1184-1189.

19. Röther J, Schellinger PD, Gass A, Sieber M, Villringer A, Fiebach $\mathrm{JB}$, et al. Effect of intravenous thrombolysis on MRI parameters and functional outcome in acute stroke $<6$ h. Stroke 2002; 33: 2438-2445.

20. Schellinger PD, Fiebach JB, Hacke W. Imaging-based decision making in thrombolytic therapy for ischemic stroke. Stroke 2003; 34: $575-583$.

21. Shih LC, Saver JL, Alger JR, Starkman S, Leary MC, Vinuela F, et al. Perfusion-weighted magnetic resonance imaging thresholds identifying core, irreversibly infarcted tissue. Stroke 2003; 34: 14251430.

22. Alberts GW, Thijs VN, Wechsler L, Kemp S, Schlaug G, Skalabrin E, et al. Magnetic resonance imaging profiles predict clinical response to early reperfusion: The diffusion and perfusion imaging 
evaluation for understanding stroke evolution (DEFUSE) Study. Ann Neurol 2006; 60: 508-517.

23. Warach S, Chien D, Li W, Ronthal M, Edelman RR. Fast magnetic resonance diffusion-weighted imaging of acute human stroke. Neurology 1992; 42: 1717-1723.

24. Baird AE, Warach S. Magnetic resonance imaging of acute stroke. J Cereb Blood Flow Metab 1998; 18: 583-609.

25. Lovblad KO, Laubach HJ, Baird AE, Curtin F, Schlaug G, Edelman $\mathrm{RR}$, et al. Clinical experience with diffusion-weighted $\mathrm{MR}$ in patients with acute Stroke. Am J Neuroradiol 1998; 19: 1061-1066.

26. Ay H, Buonanno FS, Rodorf G, Schaefer PW, Schwamm LH, Wu $\mathrm{O}$, et al. Normal diffusion-weighted MRI during stroke-like deficits. Neurology 1999; 52: 1784-1792.

27. Gonzalez RG, Schaefer PW, Buonanno FS, Schwamm LH, Budzik RF, Rordorf G, et al. Diffusion-weighted MR imaging: Diagnostic accuracy in patients imaged within 6 hours of stroke symptom onset. Radiology 1999; 210: 155-162.

28. Mintorovitch J, Moseley ME, Chileuitt L, Shimizu H, Cohen Y, Einstein PR. Comparison of diffusion- and T2-weighted MRI for the early detection of cerebral ischemia and reperfusion in rats. Mgn Reson Med 1991; 18: 39-50.

29. Moseley ME, Kucharczyk J, Mintorovitch J, Cohen Y, Kurhanewicz J, Derugin N, et al. Diffusion-weighted MR imaging of acute stroke: correlation with T2-weighted and magnetic susceptibility-enhanced MR imaging in cats. AJNR Am J Neuroradiol 1990; 11: 423-429.

30. Schellinger PD, Jansen O, Fiebach JB, Heiland S, Steiner T, Schwab S, et al. Monitoring intravenous recombinant tissue plasminogen activator thrombolysis for acute ischemic stroke with diffusion and perfusion MRI stroke. Stroke 2000; 31: 1318-1328

31. Miyabe M, Mori S, van Zilj PC, Kirsch JR, Eleff SM, Kochler $\mathrm{RC}$, et al. Correlation of the average water diffusion constant with cerebral blood flow and ischemic damage after transient middle cerebral artery occlusion in cats. J Cer Blood Flow Metab 1996; 16: 881-891.

32. Schaefer PW, Hassankhani A, Pulman C, Sorensen G, Schwamm L, Koroshetz W, et al. Charakterization and evolution of diffusion MR imaging abnormalities in stroke patients undergoing intraarterial thrombolysis. AJNR Am J Neuroradiol 2004; 25: 951-957.

33. Crisostomo RA, Garcia MM, Tong DC. Detection of diffusionweighted MRI abnormalities in patients with transient ischemic attack. Correlation with clinical characteristics. Stroke 2003; 34: 932-937.

34. Fichler J, Knab R, Reichenbach JR, Fitzek C, Weiller C, Rother J. Apparent diffusion coeficient decreases and magnetic resonance imaging perfusion parameters are associated in ischemic tissue of acute stroke patients. J Cereb Blood Flow Metab 2001; 21: 577-584.

35. Kidwell CS, Alger JR, Di Salle F, Starkman S, Villablanca P, Bentson J, et al. Diffusion MRI in patiens with transient ischemic attacks. Stroke 1999; 30: 1174-1180.

36. Fiebach JB, Schellinger PD, Jansen O, Meyer M, Wilde P, Bender $\mathrm{J}$, et al. CT and diffusion-weighted MR-imaging in randomized order: DWI results in higher accuracy and interrater variability in the diagnosis of hyperacute ischemic stroke. Stroke 2002; 33 2206-2210.

37. Fiebach JB, Schellinger PD, Heiland S, Sartor K. Convetional MRI diffusion-weighted MRI (DWI) and apparent diffusion coefficient (ADC). In: Fiebach JB, Schellinger PD, Eds. Stroke MRI 2003. Steinkopff Verlag, Darmstadt, p 21.

38. Reith W, Hasegawa Y, Latou LL, Darzinski BJ, Sotak CH, Fischer M. Multislice diffusion mapping of 3-D evolution of cerebral ischemia in rat stroke model. Neurology 1995; 45: 172-177.

39. Roberts TP, Vexler Z, Derugin N, Moseley ME, Kucharczyk J. High-speed MR imaging of ischemic brain injury folowing stenosis of the middle cerebral Artury. J cereb Blodd Flow Metab 1993; 13: 940-946.

40. Kumon Y, Zenke K, Kusunoki K, Oka Y, Sadamoto K, Ohue S, et al. Diagnostic use of isotropic diffusion-weighted MRI in patients with ischemic stroke: detection of the lesion responsible for the clinical deficit. Neuroradiology 1999; 41: 777-784.

41. Altieri M, Metz RJ, Miller C, Maeder P, Meuli R, Bogousslavsky J. Multiple brain infarcts: clinical and neuroimaging patterns using diffusion-weighted magnetic resonance. Eur Neurol 1999; 42: 76-82.
42. Šaňák D, Nosál V, Horák D, Bártková A, Zeleňák K, Herzig R, et al. Impact of diffusion-weighted MRI-measured initial cerebral infarction volume on clinical outcome in acute stroke patients with middle cerebral artery occlusion treated by thrombolysis. Neuroradiology 2006; 48: 632-9.

43. Noguchi K, Ogawa T, Inugami A, Toyoshima H, Sugawara S, Hatazawa $\mathbf{J}$, et al. Acute subarachnoid haemorrhage: MR Imaging with fluid attenuated inversion recovery pulse sequences. Radiology 1995; 196: 773-777.

44. Perkins CJ, Kahya E, Roque CT. Fluid attenuated inversion recovery and diffusion. Stroke 2001; 32: 2774-2781.

45. De Coene B, Hajnal JV, Gatehouse P, Longmore DB, White SJ, Oatridge A, et al. MR of the brain using fluid attenuated inversion recovery (FLAIR) pulse sequences. AJNR Am J Neuroradiol 1992; 13: $1555-1564$.

46. Taoka T, Iwasaki S, Nakagawa H, Fukusumi A, Kitano S, Yoshioka T, et al. Fast fluid attenuated inversion recovery (FAST-FLAIR) of ischemic lesions in the brain: comparision with T2-weighted turbo SE. Radiat Med 1996; 14: 127-131.

47. Linfante I, Llinas RH, Caplan LR, Warach S. MRI features of intracerebral hemorrhage within 2 hours from symptom onset. Stroke 1999; 30: 2263-2267.

48. Kidwell CS, Saver JL, Villablanca JP, Duckwiler G, Fredieu A, Gough K, et al. Magnetic resonance imaging detection of microbleeds before thrombolysis: an emerging application. Stroke 2002; 33: 95-98.

49. Nighoghossian N, Hermier M, Adeleine P, Blanc-Lasserre K, Derex $\mathrm{L}$, Honnoral J, et al. Old microbleeds are potential risk for cerebral bleeding after ischemic stroke: a gradient-echo $\mathrm{T} 2$-weighted brain MRI study. Stroke 2002; 33: 735-742.

50. Keller P. Time of flight magnetic resonance angiography. Neuroimaging Clin N Am 1992; 4: 639-656.

51. Blatter DD, Parker DL, Ahn SS Bahr AL, Robison RO, Schwartz RB, Jolesz FA, et al. Cerebral MR angiography with multiple overlapping thin slab acquisition. Radiology 1992; 183: 379-389.

52. Warach S, Li W, Ronthal M, Edelman RR. Acute cerebral ischemia: evaluation with dynamic contrast-enhanced MR imaging and MR angiography. Radiology 1992; 182: 41-47.

53. Evans AJ, Richardson DB, Tien R, Mac Fall JR, Hedlund LW, Heinz ER, et al. Poststenotic signal loss in MR angiography; effects of echo time, flow compensation and fractional echo. AJNR Am J Neuroradiol 1993; 14: 721-729.

54. Fujita N, Hirabuki N, Fujii N, Hashimoto T, Miura T, Sato T, et al. MR Imaging of middle cerebral artery stenosis and occlusion: Value of MR angiography. AJNR Am J Neuroradiol 1994; 15:335341.

55. Korogi Y, Takahashi M, Mabuchi N, Miki H, Shiga H, Watabe T, et al. Intracranial vascular stenosis and occlusion: diagnostic accuracy of three-dimensional, Fourier transform, time-of-flight MR angiography. Radiology 1994; 193: 187-193.

56. Wong KS, Lam WWM, Liang E, Huang YN, Chan YL, Kay R. Variability of magnetic resonance angiography and computed tomography angiography in grading middle cerebral artery stenosis. Stroke 1996; 27: 1084-1087.

57. Zaidat OO, Zahuranec DB, Ubogu EE, Fernandes-Filho JA, Suarez JI, Sunshine JL, et al. Asymptomatic middle cerebral artery stenosis diagnosed by magnetic resonance angiography. Neuroradiology 2004; 46:49-53

58. Edelman RR, Mattle HP, O'Reilly GV, Wentz KU, Cheby L, Zhao B. Magnetic resonance imaging of flow dynamics in circle of Willis. Stroke 1990; 21: 56-65.

59. Hartkamp MJ, van der Grond J, van Everdingen KJ, Hillen B, Mali WPTM. Circle of Willis collateral flow investigated by magnetic resonance angiography. Stroke 1999; 30: 2671.

60. Lee LJ, Kidwell CS, Alger J, Starkmann S, Saver JL. Impact on stroke subtype diagnosis of early diffusion-weighted magnetic resonance imaging and magnetic resonance angiography. Stroke 2000; 31: 1081.

61. Masaryk TJ, Modic MT, Ross JS, Ruggieri PM, Laub GA, Lenz $\mathrm{GW}$, et al. Intracranial circulation: preliminary clinical experience with three-dimensional volume MR angiography. Radiology 1989; 171: 793-799. 
62. Patel MR, Klufas RA, Kim D, Kramer J, Polak JF, Skillman JJ, et al. Preoperative assessment of the carotid bifurcation: can magnetic resonance angiography and duplex ultrasonography replace contrast arteriography? Stroke 1995; 26: 1753-1758.

63. Butz B, Dorenbeck U, Borisch I, Zorger N, Lenhart M, Feuerbach $\mathrm{S}$, et al. High-resolution contrast-enhanced magnetic resonance angiography of the carotid arteries using fluoroscopic monitoring of contrast arrival: diagnostic accuracy and interobserver variability. Acta Radiol 2004; 45: 164-70.

64. Van Bemmel CM, Viergever MA, Niessen WJ. Semiautomatic segmentation and stenosis quantification of 3D contrast-enhanced MR angiograms of the internal carotid artery. Magn Reson Med 2004; 51: 753-60.

65. Townsend TC, Saloner D, Pan XM, Rapp JH. Contrast materialenhanced MRA overestimates severity of carotid stenosis, compared with 3D time-of-flight MRA. J Vasc Surg 2003; 38: 36-40.

66. Huston J, Fain SB, Wald JT. Carotid artery: elliptic centric contrastenhanced MR angiography compared with conventional angiography. Radiology 2001; 218: 138-143.

67. Lenhart M, Framme N, Volk M, Strotzer M, Manke C, Nitz WR, et al. Time-resolved contrast-enhanced magnetic resonance angiography of the carotid arteries: diagnostic accuracy and inter-observer variability compared with selective catheter angiography. Invest Radiol 2002; 37: 535-41.

68. Rosen BR, Belliveau JW, Chin D. Perfusion imaging by nuclear magnetic resonance. Magn Reson Q 1989; 5: 263-281.

69. Kucharczyk J, Mintorovitch J, Asgari HS, Moseley ME. Diffusion/ perfusion imaging of acute cerebral ischemia. Magn Reson Med 1991; 311-315

70. Copen WA, Sorensen AG. Perfusion-weighted MRI in Stroke. In: Davis S, Fisher M, Warach S. Magnetic resonance imaging in stroke. Cambridge University Press 2003, pp 154-155.

71. Schellinger PD, Fiebach JB, Heiland S, Sartor K. Perfusionweighted MRI. In: Fiebach JB, Schellinger PD eds. Stroke MRI. Steinkopff Verlag, Darmstadt 2003, pp 23-29

72. http://www.eso-stroke.org/pdf/ESO_Extended_Thrombolysis_ KSU.pdf

73. Hacke W, Kaste M, Bluhmki E et al., Thrombolysis with Alteplase 3 to 4.5 Hours after Acute Ischemic Stroke. N Engl J Med 2008; 359: 1317-29.

74. Baird AE, Benfield A, Schlaug G, Siewert B, Lovblad KO, Edelman $\mathrm{RR}$, et al. Enlargement of human cerebral ischemic lesion volumes measured by diffusion-weighted magnetic resonance imaging. Ann Neurol 1997; 41: 581-589.

75. Warach S. Thrombolysis in stroke beyond three hours: Targeting patients with diffusion and perfusion MRI. Ann Neurol 2002; 51: $11-13$.

76. Butcher KS, Parsons M, MacGregor L, Barber PA, Chalk J, Bladin $\mathrm{C}$, et al. Refining the perfusion-diffusion mismatch hypothesis. Stroke 2005; 36: 1153-1159.

77. Kidwell CS, Alger JR, Saver JL. Beyond mismatch: evolving paradigms in imaging the ischemic penumbra with multimodal magnetic resonance imaging. Stroke 2003; 34: 2729-2735.

78. Lenzi GL, Frackowiak RS, Jones T. Cerebral oxygen metabolism and blood flow in human cerebral ischemic infarction. J Cereb Flow Metab 1982; 2: 321-335.

79. Wise RJ, Bernardi S, Frackoviak RS, Jones T, Legg NJ, Lenzi GL. Measurement of regional cerebral blood flow, oxygen extraction ratio and oxygen utilisation in stroke patients using positron emission tomography. Ex Brain res 1992; 182-186.

80. Hakim AM, Pokrupa RP, Villanueva J, Diksic M, Evans AC, Thompson CJ, et al. The effect of spontaneous reperfusion on metabolite function in early human cerebral infarcts. Ann Neurol 1987; 14: 892-902.

81. Heiss WD, Graf R, Wienhard K, Lottgen J, Saito R, Fujita T, et al. Dynamic penumbra demonstrated by sequential multitracer PET after middle cerebral artery occlusion in cats. J Cereb Blood Flow Metab 1994; 14: 892-902.

82. Barber PA, Parsons MW, Desmond PM, Bennett DA, Donnan GA, Tress BM, et al. The use of PWI and DWI measures in "Proof-ofConcept" Stroke Trials. J Neuroimaging 2004; 14:123-132.

83. Chalela JA, Kang DW, Luby M, Ezzeddine M, Latour LL, Todd JW, et al. Early magnetic resonance imaging findings in patients receiving tissue plasminogen activator predict outcome: Insights into the pathophysiology of acute stroke in the thrombolysis era. Ann Neurol 2004; 55: 105-112.

84. Hacke W, Albers G, Al Rawi Y, Bogousslavsky J, Davalos A, Eliasziw M, et al. The Desmoteplase in Acute Ischemic Stroke Trial (DIAS): A phase II MRI-based 9-hour window acute stroke thrombolysis trial with intravenous desmoteplase. Stroke 2005; 36 : 66-73.

85. Ribo M, Molina CA, Rovira A, Quintana M, Delgado P, Montaner $\mathrm{J}$, et al. Safety and efficacy of intravenous tissue plasminogen activator stroke treatment in the 3- to 6-hour window using multimodal transcranial Doppler/MRI selection protocol. Stroke 2005; 36: 602 606

86. The ATLANTIS, ECASS, and NINDS rt-PA Study Group Investigators. Association of outcome with early stroke treatment: pooled analysis of ATLANTIS, ECASS, and NINDS rt-PA stroke trials. Lancet 2004; 363: 768-774.

87. Köhrmann M, Jüttler E, Fiebach JB, Huttner HB, Siebert S, Schwark C, et al. MRI versus CT-based thrombolysis treatment within and beyond the $3 \mathrm{~h}$ time window after stroke onset: a cohort study. Lancet Neurol 2006; 5: 661-667.

88. Schellinger PD, Thomalla G, Fiehler J, Kohrmann M, Molina CA, Neumann-Haefelin T, et al. MRI-based and CT-based thrombolytic therapy in acute stroke within and beyond established time windows: an analysis of 1,210 patients. Stroke 2007; 38: 2640-2645.

89. Simonsen CZ, Ostergaard L, Smith DF, Vestergaard-Poulsen P, Gyldensted C. Comparison of gradient- and spin-echo imaging: CBF, CBV and MTT measurements by bolus tracking. J Magn Reson Imaging 2000; 12: 411-416.

90. Smith AM, Grandin CB, Duprez T, Mataigne F, Cosnard G. Whole brain quantitative CBF, CBV and MTT measurements using MRI bolus tracking: implementation and application to data acquired from hyperacute stroke patients. Magn Reson Imaging 2000; 12: 400-410.

91. Zaharchuk G, Yamada M, Sasamata M, Jenkins BG, Moskowitz MA, Rosen BR. Is all perfusion-weighted magnetic resonance imaging for stroke equal? The temporal evolution of multiple hemodynamic parameters after focal ischemia in rats correlated with evidence of infarction. J Cereb Blood Flow Metab 2000; 20: 13411351.

92. Grandin CB, Duprez TP, Smith AM, Oppenheim C, Peeters A, Robert AR, Cosnard G. Which MR-derived perfusion parameters are the best predictors of infarct growth in hyperacute stroke? Comparative study between relative and quantitative measurements. Radiology 2002; 223: 361-370

93. Kane I, Sandercock P, Wardlaw J. Magnetic resonance perfusion diffusion mismatch and thrombolysis in acute ischemic stroke: A systematic review of the evidence to. J Neurol Neurosurg Psychiatry. 2006 Oct 20; 10.1136/jnnp.2006.100347.

94. Barber PA, Davis SM, Darby DG, Desmond PM, Gerraty RP, Yang $\mathrm{Q}$, et al. Absent middle cerebral artery flow predict the presence and evolution of the ischemic penumbra. Neurology 1999; 52: 1125-1132.

95. Ribo M, Molina CA, Rovira A, Quintana M, Delgado P, Montaner $\mathrm{J}$, et al. Safety and efficacy of intravenous tissue plasminogen activator stroke treatment in the 3- to 6-hour window using multimodal transcranial Doppler/MRI selection protocol. Stroke 2005; 36: 602606

96. Dávalos A, Blanco M, Pedraza S, Leira R, Castellanos M, Pumar JM et al. The clinical-DWI mismatch. A new diagnostic approach to the brain tissue at risk of infarction. Neurology 2004; 62: 2187 2192

97. Prosser J, Butcher K, Allport L, Pardone M, MacGregor L, Reskond $\mathrm{P}$, et al. Clinical-diffusion mismatch predicts the putative penumbra with high specificity. Stroke 2005; 36: 1700-1704.

98. Lansberg MG, Thijs VN, Hamilton S, Schlaug G, Bammer R, Kemp $\mathrm{S}$, et al. Evaluation of the clinical-diffusion and perfusion-diffusion mismatch models in DEFUSE. Stroke 2007; 38: 1826-1830.

99. Sanak D, Bartkova A, Horak D, Herzig R, Vlachova I, Zapletalova $\mathrm{J}$, et al. Does clinical-diffusion mismatch predict good clinical outcome in acute stroke patients treated by intravenous thrombolysis? Eur J Neurol 2007; 14 (Suppl 1): 169. 
